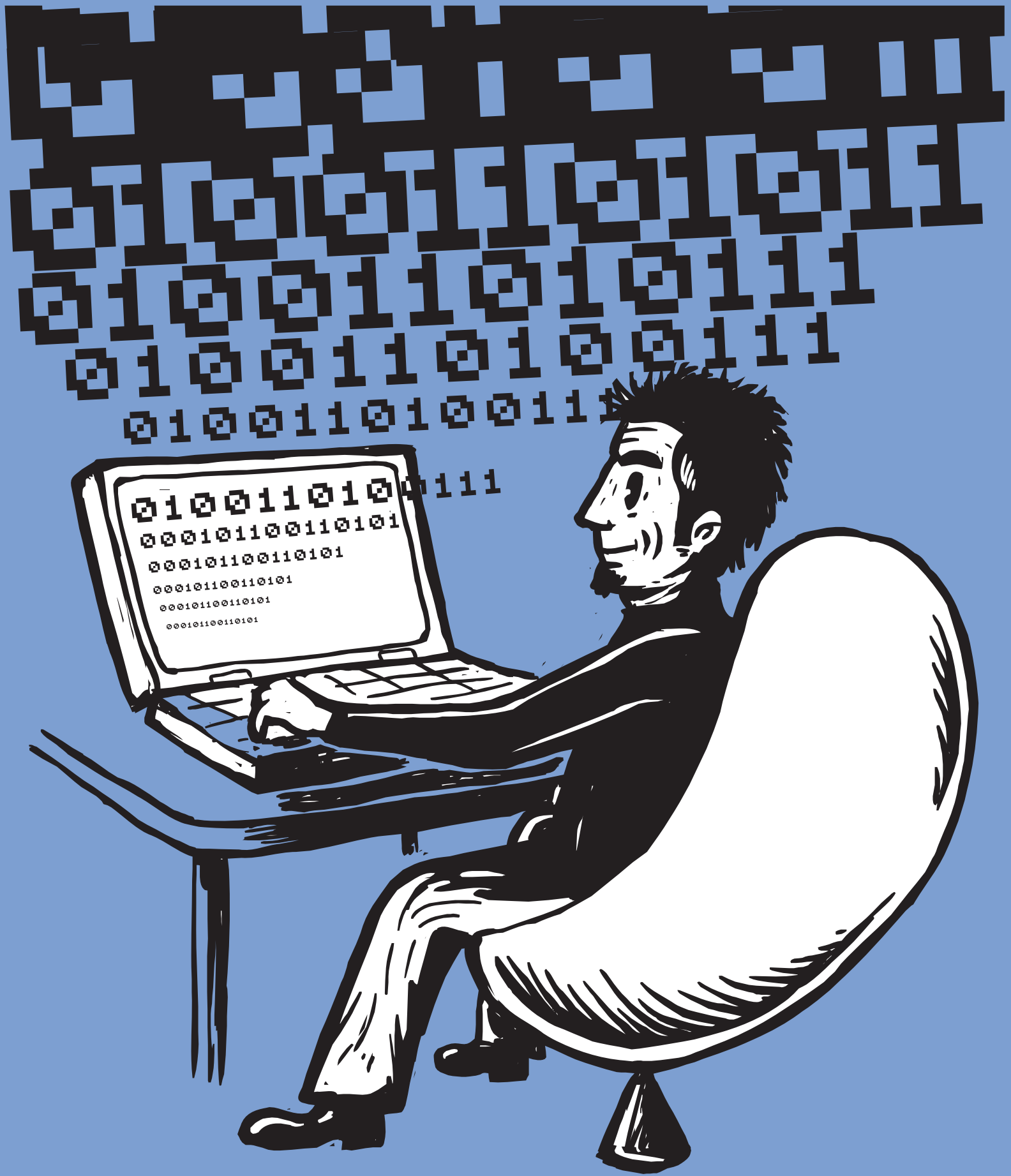




\section{Mulher e tecnologia: a assimilação e utilização do mundo digital por executivas de Comunicação}

Ana Maria Franchon

- Mestranda do Programa de Ciências da Comunicação, especialista em Gestão Estratégica em Comunicação Organizacional e Relações Públicas (Gestcorp) e bacharel em Comunicação Social com habilitação em Relações Públicas pela Escola de Comunicações e Artes da Universidade de São Paulo (ECA-USP)

- Colaboradora da Asociación Latinoamericana de Investigadores de la Comunicación (ALAIC)

- anafranchon@yahoo.com

- anafranchon@hotmail.com 
Resumo

A recente entrada da mulher no mundo do trabalho do homem veio acompanhada de uma série de rápidas inovações tecnológicas e a sociedade parece ainda não ter se adaptado totalmente a essas mudanças. Neste artigo, o objetivo é entender como se dá a relação da mulher pós-moderna com a tecnologia no universo de trabalho da Comunicação Organizacional.

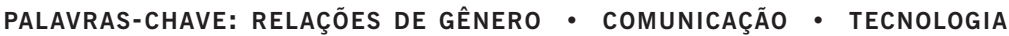

\section{Abstract}

The woman's recent entrance in the world of man's work has come accompanied of a series of fast technological innovations and the society seems still not to have totally adapted to those changes. In this article, the objective is to understand the post-modern woman's relationship with technology in the universe of work of the Organizational Communication.

KEY WORDS: GENDER RELATIONSHIPS - COMMUNICATION - TECHNOLOGY

\section{Resumen}

La reciente entrada de la mujer en el mundo del trabajo del hombre vino acompañada de una serie de rápidas innovaciones tecnológicas y la sociedad todavía parece no tenerse adaptado totalmente a esos cambios. En este artículo, el objetivo es entender la relación de la mujer post-moderna con la tecnología en el universo de trabajo de la Comunicación Organizacional.

PALABRAS-CLAVE: RELACIONES DE GÉNERO - COMUNICACIÓN • TECNOLOGÍA 
$\mathrm{N}$ as últimas décadas, o modelo de gestão organizacional sofreu alterações, desenvolvendo mecanismos para adaptação às rápidas e numerosas transformações econômicas e tecnológicas pelas quais o mundo tem passado. A organização, como sistema aberto, passou a ser fortemente influenciada por quatro novos paradigmas: nova tecnologia, nova ordem geopolítica, novo ambiente empresarial e nova empresa (KUNSCH, 2003: 58).

Entre os paradigmas citados, a questão das novas tecnologias abarca o desenvolvimento de novas metas para a Tecnologia de Informação (TI) e uma computação em rede, aberta e centrada no usuário. Na área de Comunicação Organizacional, a preocupação não poderia ser diferente: é crescente o esforço para a utilização adequada e integrada dessas novas tecnologias ao plano de Comunicação, destacando-se o uso da tecnologia para melhorar o relacionamento entre a organização e seus públicos.

O interesse pelo tema da relação entre as mulheres, tecnologia e a Comunicação surgiu do questionamento de um dos executivos da Palm do Brasil, para quem desenvolvi trabalhos na área de assessoria de comunicação: "Não estamos conseguindo 'vender' para as mulheres. Será que as mulheres são avessas à tecnologia?”.

Sabe-se que hoje existe um crescente número de mulheres que necessita e utiliza as mais recentes tecnologias, já que a presença da mulher na sociedade pós-moderna é, também, cada vez mais significativa. Além de estar invadindo o mercado de trabalho do homem, as mulheres passaram a ocupar cargos elevados nas organizações, que exigem o conhecimento e domínio na utilização de tecnologia.

Dentro deste cenário de mudanças, a área de Comunicação das empresas modernas ganhou destaque, ocupando uma posição estratégica, já que detém o poder da informação. As mulheres, que até então exerciam um papel secundário na sociedade, estão cada vez mais presentes também nos departamentos de Comunicação e, nesta condição, acabam como detentoras de dois tipos de poder: o poder da informação e o poder conferido pelo uso da tecnologia para difundir a informação.

A questão é que as transformações sociais ocorridas nas últimas décadas do século XX foram responsáveis por uma grande mudança no cenário do mundo do trabalho no século XXI. Porém, a sociedade ainda está precariamente preparada para lidar com esta nova situação e existem poucos estudos que tratam da relação da mulher com este novo instrumento de poder, a tecnologia. 
MULHER E TECNOLOGIA: A ASSIMILAÇÃO E UTILIZAÇÃO DO MUNDO DIGITAL POR EXECUTIVAS

DE COMUNICAÇÃO • ANA MARIA FRANCHON

\section{A evolução do papel da mulher na sociedade através dos tempos}

Para compreender a recente relação da mulher com a tecnologia, faz-se necessário um breve histórico da evolução de seu papel social. Até pouco tempo, o sistema social dominante era o patriarcado, no qual o homem, além de detentor do poder financeiro, também exercia o papel de chefe da família, responsável pela tomada de decisões.

O sociólogo Bourdieu (1930) acredita que a diferença anatômica entre homens e mulheres influencia a justificativa da divisão social do trabalho: aos homens são atribuídas qualidades como força, razão e atividade, enquanto que as mulheres são vistas como frágeis, sensíveis e passivas/submissas. Ao mesmo tempo que essa diferença anatômica é utilizada para explicar a divisão social do trabalho, é a própria visão social que determina essas diferenças anatômicas, ou seja, a relação é circular.

A dominação da visão androcêntrica do mundo é resultado da perpetuação de hábitos, crenças e atitudes que, em grande parte, é feita pelas estruturas de dominação, como a Igreja, a Família e a Escola e, por que não adicionar, o papel do Estado que, só no último século, começou a desenvolver políticas para garantir os direitos das mulheres.

Segundo Esther Herráes (apud ARAÚJO, SANCHES e LOPES, 1999), “[...] a presença feminina na ciência e tecnologia é uma quebra de paradigma. Este fato se justifica em decorrência do desigual acesso educacional do sexo feminino no mundo. Fazer um balanço de como esse acesso educacional se expressa, sem cair no exagero, é extremamente difícil”.

O século XX foi marcado por uma série de mudanças em todos os campos e, com relação ao patriarcado e à dominação masculina, o marco para o início da mudança no Brasil foi, sem dúvida, a conquista do direito ao voto em 1934 e a possibilidade da candidatura de mulheres a cargos políticos. Esta conquista feminina teve um reflexo importante mais tarde, na década de 60 , quando iniciou-se o movimento feminista. A chamada revolução cultural foi responsável pelo questionamento aberto sobre o papel das mulheres na sociedade.

O movimento feminista é o marco da entrada da mulher na História do mundo. O fato de a mudança ter início com sua inserção na política, área marcada pelo poder que até então era negado à mulher, carregou o movimento feminista de ideologia política. Além disso, o apelo econômico para a inserção das mulheres no mercado de trabalho já vinha sendo utilizado desde a Segunda Guerra Mundial, quando a força do trabalho feminino sustentou a economia de diversos países, já que os homens haviam partido para a guerra. 
Para uma competição mais justa com os homens no mercado de trabalho, as mulheres começaram a freqüentar cada vez mais escolas e universidades e eram estimuladas para tanto. Na realidade, estava claro para o movimento feminista que o nível de escolaridade das mulheres acabaria influenciando a queda do argumento de que elas não serviam para trabalhos intelectualizados por não estarem preparadas.

Nos anos 70, houve um distanciamento do movimento feminista da política. A idéia era que o movimento partisse para a ação, não ficando apenas com ideologias no papel, com reivindicações claras, como a diminuição das diferenças salariais entre homens e mulheres.

Nos anos 80, com a introdução do termo gênero para os estudos relacionados à divisão de papéis sociais, o estudo da condição feminina acaba deixando de ser tratado apenas pelas ciências sociais, política e filosofia, para expandir como tema de estudo de diversas áreas do conhecimento humano. "É ainda nos anos 80 que a importância do movimento feminista é reconhecida mundialmente pela Organização das Nações Unidas, que decretou como a década das mulheres os anos compreendidos entre 1975 e 1985" (DIAS, 2001: 18).

\section{A mulher em tempos pós-modernos}

Alguns estudiosos consideram que as numerosas transformações que estão ocorrendo nos últimos anos e sua velocidade vertiginosa caracterizam um novo período histórico, que foi denominado pós-modernidade. Devido às suas características, a era acaba favorecendo o modo de pensar feminino, já que valoriza a estética em lugar da racionalidade modernista. "A experiência do tempo e do espaço se transformou, a confiança na associação entre juízos científicos e morais ruiu, a estética triunfou sobre a ética como foco primário de preocupação intelectual e social, as imagens dominaram as narrativas [...]” (HARVEY, 1993: 293).

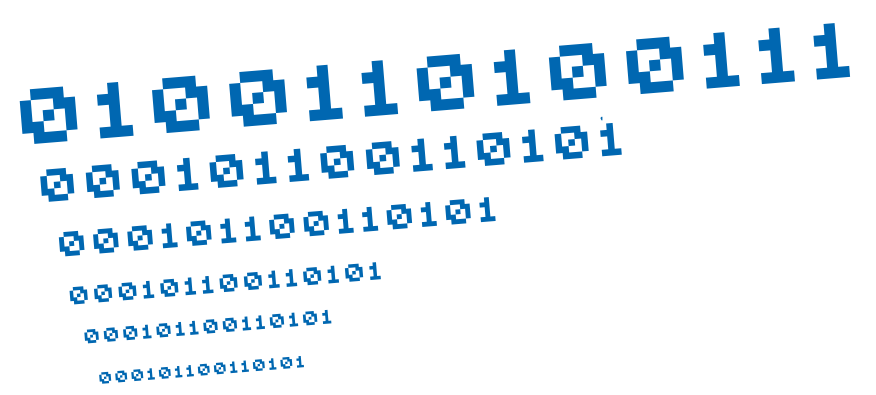


Ainda mais, a pós-modernidade e a globalização são movimentos que favorecem a intensificação da comunicação e uma maior circulação de informações. No Brasil, em especial, o desenvolvimento da Comunicação foi favorecido pelo fim da ditadura e democratização em todos os níveis, inclusive da informação. Porém, os novos meios de comunicação de massa tanto abriram novos canais de informação como não conseguiram, ainda, acompanhar a intensa velocidade da metamorfose da sociedade, provocada pela inserção das modernas tecnologias.

O trabalho

Foi na Sociedade Industrial que a tecnologia chegou para substituir o trabalho escravo. Está claro para a Sociedade Industrial que o trabalho dentro das fábricas divide a família e a função da mulher acaba sendo a de ligação entre a vida familiar e a vida do trabalho. Além disso, o caráter racional do trabalho na indústria parece querer expulsar tudo o que não o é, que é a dimensão emotiva, estética:

"[...] a nova lei estabelece que estas são coisas de mulher, que devem ser geridas dentro das paredes da casa. A esfera pública é gerida pelos homens, que para isso usam, justamente, a razão. A sociedade é masculina, por definição. A sociedade nunca foi tão masculina como na idade industrial" (DE MASI, 2000: 63).

Só há algumas décadas, com a introdução da informática, é que o trabalho está voltando para dentro dos lares das pessoas. O trabalho tem deixado de ser manual para ser intelectual, já que as atividades repetitivas estão sendo desempenhadas pelas máquinas. As atividades criativas são cada vez mais valorizadas na nova sociedade pós-industrial e esse é um dos fatores que favorece a entrada das mulheres nesse novo universo do trabalho.

\section{A inserção da mulher no mundo do trabalho do homem}

O século XX é marcado pela inserção das mulheres nas mais variadas posições, cargos e profissões. O mundo do trabalho do homem começa, aos poucos, a ser cada vez mais feminino. No Brasil, a estagnação do crescimento econômico no final dos anos 1970 devido à crise do petróleo estimulou a entrada das mulheres no mercado de trabalho. Por um lado, as empresas começaram a preferir a mão-de-obra feminina devido ao pagamento de salários mais baixos e, de outro lado, nas famílias, a queda da renda familiar abriu as portas do mercado de trabalho para as mulheres.

O fato é que hoje a questão não é mais sobre a busca pela igualdade, mas sobre a conquista de um espaço feminino na sociedade, independentemente do espaço dos homens. Segundo um estudo feito pelo Ibope Solution sobre a mulher do novo século (apresentado no evento Maximídia 2004), “[...] as mulheres são diferentes entre si e querem 
MULHER E TECNOLOGIA: A ASSIMILAÇÃO E UTILIZAÇÃO DO MUNDO DIGITAL POR EXECUTIVAS DE COMUNICAÇÃO • ANA MARIA FRANCHON

ser tratadas assim. Há mais espaço para tecnologia e modernidade em suas vidas [...]. O desafio hoje é como conciliar suas novas funções na sociedade”.

A chamada dupla jornada de trabalho, que é a conjugação das atividades domésticas (cuidados com a casa e a família) com as atividades profissionais (entrada da mulher no mercado de trabalho), hoje passou a ser tripla. A conscientização de sua posição desfavorável na competição pelo mercado de trabalho leva cada vez mais mulheres às escolas e universidades, à procura de uma formação intelectual mais justa. Infelizmente, a entrada da mulher no mercado de trabalho do homem não aconteceu em conjunto com mudanças da sociedade. Segundo Freitas (1987: 75-76),

"[...] a entrada da mulher no mercado de trabalho não se fez acompanhar das reestruturações necessárias na sociedade (creches, pessoal de serviços), acabando por sobrecarregar a mulher com a dupla jornada de trabalho, pois o homem, via de regra, não dispõe de seu tempo para as crianças e o lar, dificultando para a maioria das mulheres a competição pelo poder".

Segundo estudos da Fundação Americana de Mulheres de Negócios, acredita-se que existam, hoje, 9,2 milhões delas exercendo cargos de liderança em organizações de informática no mundo todo. Mesmo assim, por incrível que pareça, ainda existe o preconceito de que as mulheres que ocupam altos cargos têm que pagar com um menor sucesso na ordem doméstica e vice-versa.

\section{A Revolução Tecnológica e a Comunicação}

A Revolução Tecnológica Informacional, que acontece em meio à conturbada era pósmoderna, "[...] está reconfigurando o conjunto das sociedades humanas em todos os seus aspectos, implodindo barreiras de Tempo e Espaço, colocando a Informação como elemento central de articulação das atividades humanas" (LEMOS e PALACIOS, 2001: 5).

Graças à introdução de modernas invenções tecnológicas, hoje se pode ter acesso a notícias de qualquer parte do mundo, instantaneamente, conhecer cidades, museus, enfim, o universo de informações disponíveis foi rapidamente ampliado. Uma tendência que acontece com o desenvolvimento tecnológico é a personalização dos meios de comunicação de massa. "Uma teoria amplamente difundida afirma que a individualização é a extrapolação do narrowcasting - parte-se de um grupo grande para um grupo pequeno; depois, para um grupo menor ainda; por fim, chega-se ao indivíduo" (NEGROPONTE, 1995: 158). Por sua vez, a personalização dos meios de comunicação estimula a comunicação de mão-dupla, a troca de informações em veículos cada vez mais interativos.

As distâncias foram reduzidas e a informação, agora, é instantânea. A socialização do indivíduo acontece em comunidades e bairros digitais. A informação está sendo digi- 
talizada, deixando de ser física para transformar-se em bits. No mundo digital, o meio não é mais a mensagem, é apenas uma das formas que ela assume, variando de acordo com a tecnologia empregada para sua disseminação.

A secretária eletrônica ou o uso do correio de voz apresentam outra característica da revolução tecnológica informacional, que é a possibilidade de assincronia. "A vantagem que ambos (a secretária eletrônica e o correio de voz) oferecem tem menos a ver com a vez e mais com a possibilidade de processar tais mensagens off-line e a qualquer momento. Em vez de se envolver uma pessoa sem necessidade numa conversa on line, deixa-se uma mensagem" (NEGROPONTE, 1995: 161). A previsão de muitos especialistas em tecnologia é a de que, no futuro, todos os meios de comunicação (inclusive a televisão e o rádio, por exemplo) assumirão a característica de assincronia, quando não houver a necessidade de transmissão de informações em tempo real.

Obviamente que todas as mudanças afetaram, de uma maneira singular, a comunicação. Em poucos anos, pode-se citar as seguintes transformações:

- foram criados os jornais on line, com linguagem e posicionamento no tempo e no espaço completamente distintos de tudo o que vinha sendo feito;

- a intranet surgiu como uma rede interna de informações específicas para o público interno;

- os diários pessoais passaram a ser públicos, sendo veiculados em sites pessoais no formato de blogs e fotoblogs;

- pessoas que não se encontram há anos estão formando comunidades no Orkut;

- reuniões entre cidades de várias partes do mundo acontecem graças a aparelhos de videoconferência, que transmitem som e imagem em tempo real.

E tudo isso, provavelmente, daqui há alguns anos, quando alguém tiver a curiosidade de ler este artigo, estará completamente obsoleto. O problema, agora, parece não ser mais a escassez de informações que caracterizou a sociedade durante tanto tempo, mas aprender a selecionar o que é mais importante para cada um.

Do outro lado, o do emissor das informações, é preciso que haja um esforço para diferenciar as mensagens emitidas para que consigam atingir o receptor. Mais do que isso, é preciso o domínio das ferramentas tecnológicas, acompanhar esta revolução, para que não se perca tempo com ações de comunicação que não levam a lugar nenhum.

Pode-se dizer que hoje em dia existe um certo modismo na utilização dos modernos recursos digitais para a comunicação, o que acaba levando algumas organizações a utilizá-los de maneira indiscriminada e sem critérios. Os problemas de inadequação no uso de meios digitais ocorrem, principalmente, porque a comunicação digital deve es- 
tar integrada à um plano estratégico de Comunicação, considerando sua ligação com os demais instrumentos da Comunicação Institucional e Mercadológica.

No caso das organizações, meios como a Internet, intranet e o e-mail marketing devem ser estudados e bem conhecidos pelos comunicadores, a fim de que, sabendo suas funções e especificidades, sejam devidamente utilizados. A Internet, por exemplo, é um meio de rápida exposição, já que em geral o usuário fica pouco tempo navegando no mesmo site, além de ser um meio que está sempre em movimento. Mesmo na comunicação digital como um todo, o fator humano é indispensável, já que são ferramentas que pressupõem a interatividade, combinando elementos como a imagem, o som e a escrita.

Outras características importantes dos meios digitais são a linguagem não-linear (hipermídia), flexibilidade, rapidez, convergência e a criação de comunidades virtuais. Quando comparados com os outros meios de comunicação, enquanto a comunicação de massa preza pela homogeneização e uniformização da informação, é necessário aprender a usar a comunicação digital de forma dirigida para criar um diferencial (a Internet não é mídia de massa) - a quantidade de informações que se recebe é muito grande e, por isso, muito acaba sendo perdido. O conhecimento sobre o público receptor é outro aspecto importante: as ferramentas devem sempre ser testadas antes de serem divulgadas e são importantes as pesquisas contínuas de mercado e de opinião, além do uso de software de auditoria para monitoramento. O conteúdo tem que estar de acordo com a cultura organizacional e suas ações, mostrando-se relevante para o público, além de respeitar as políticas de privacidade e estimular o feedback (participação, interação).

Enfim, os comunicadores, de uma maneira geral, devem estar atentos às inovações tecnológicas e procurar utilizá-las apropriadamente, de forma integrada com os outros instrumentos existentes, alinhadas à cultura organizacional e ao plano estratégico elaborado.

\section{A mulher e a Comunicação}

O protagonismo feminino no mercado de trabalho da comunicação é um tema que vem sendo bastante estudado por pesquisadores de todo o mundo. Na área de Relações Públicas, por exemplo, o pesquisador americano James E. Grunig (2003: 71) destaca que, "nos Estados Unidos, a transformação das Relações Públicas numa função da administração foi afetada pelo grande número de pessoas do sexo feminino que se encontram na profissão. Aproximadamente $75 \%$ dos estudantes de Relações Públicas e $60 \%$ dos profissionais ativos são mulheres".

No Brasil, várias pesquisadoras da Comunicação também levantaram dados que confirmam esta tendência. Em outubro de 2002, o tema do VI Colóquio Internacional 


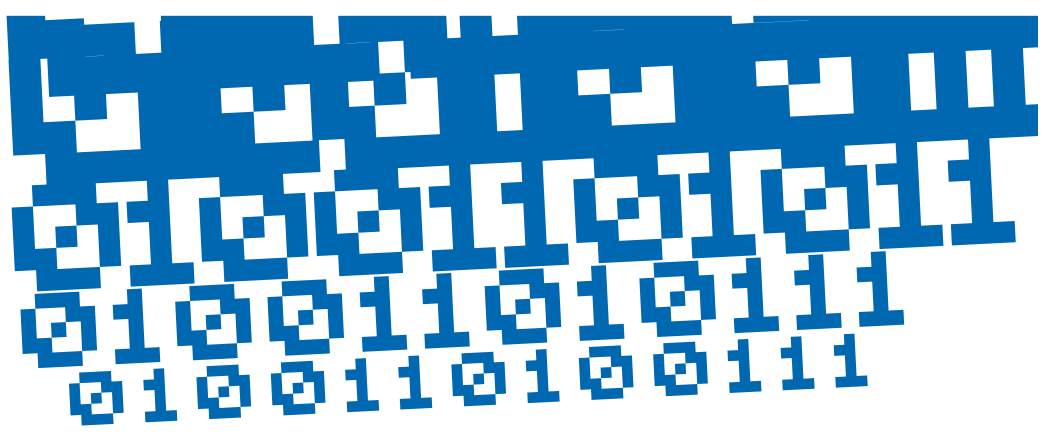

sobre a Escola Latino-Americana de Comunicação (Celacom) tratou exatamente da participação da mulher nos estudos comunicacionais latino-americanos. Neste evento, a professora Margarida Kunsch apresentou um levantamento quantitativo da produção intelectual da Escola de Comunicações e Artes da Universidade de São Paulo desde a década de 1960. Seus estudos demonstraram que "[...] as mulheres participaram ativamente das pesquisas em Comunicação, mas que, embora responsáveis por mais dissertações e teses, a produção de livros e artigos mostrou superioridade masculina no período" (PESSONI, 2003: 220).

No mesmo artigo da Revista Comunicação e Sociedade, sobre o VI Celacom, Pessoni ainda destaca os dados das pesquisadoras do Grupo Comunicacional de São Bernardo do Campo, Elizabeth Gonçalves e Maria Cristina Gobbi. No estudo, foi feito um levantamento de 326 dissertações de mestrado e 15 teses de doutorado produzidas de 1981 a 2001. "Nesse trabalho, as professoras da Umesp informaram que as mulheres foram responsáveis por $52 \%$ das dissertações e $40 \%$ das teses defendidas [...]" (PESSONI, 2003: 220).

Quanto ao mercado de trabalho, a preocupação com o tema também demonstrou-se presente em uma pesquisa da Associação Brasileira de Comunicação Empresarial (Aberje). O Instituto Aberje de Pesquisa apresentou um relatório, em março de 2005, delineando um perfil feminino para as mulheres do mercado de comunicação. Dentre os principais resultados, pode-se destacar:

- as equipes de comunicação, em sua maioria, são enxutas e formadas por mulheres: $63,65 \%$ têm menos de oito pessoas e $65 \%$ têm mais mulheres que homens;

- quanto à formação das mulheres que trabalham com Comunicação Corporativa, $24,95 \%$ são jornalistas e apenas $8,8 \%$, relações-públicas;

- em relação ao estado civil das mulheres entrevistadas, houve um equilíbrio entre mulheres casadas e solteiras, estando a maioria na faixa etária entre 25 e 40 anos de idade $(65,5 \%)$;

- a divisão das funções ficou bastante clara, sendo reservadas para as mulheres as 
MULHER E TECNOLOGIA: A ASSIMILAÇÃO E UTILIZAÇÃO DO MUNDO DIGITAL POR EXECUTIVAS DE COMUNICAÇÃO • ANA MARIA FRANCHON

áreas de Comunicação Interna e relações com a comunidade, enquanto que os homens ficam com a comunicação com o Governo e gestão de crise;

- na opinião das entrevistadas, as mulheres têm melhor relacionamento interpessoal $(75 \%)$ e as empresas preferem os homens em cargos de diretoria ( $70 \%$ das entrevistadas).

Diante dos dados levantados, fica evidente a importância e contribuição feminina para a área de comunicação, tanto no campo científico como no mercado de trabalho. Porém, alguns estereótipos ainda são apontados, ficando as mulheres com as funções de mediação, relacionamento, enquanto que aos homens cabem as funções mais estratégicas e que envolvem tomada de decisão.

Um estereótipo preocupante levantado na pesquisa da Aberje foi o fato de que os entrevistados acreditam que os cargos de chefia são destinados, ainda, em sua maioria, aos homens, que, por conseguinte, acabam realmente ganhando salários mais altos. Esta é também uma preocupação de Grunig (2003: 71), ao ressaltar que "nos Estados Unidos, as mulheres tradicionalmente têm sido excluídas do exercício de funções gerenciais. [...] É evidente que o crescimento das Relações Públicas como função gerencial requer que os pesquisadores encontrem meios de dar maior presença às mulheres que praticam Relações Públicas.”

A mulher e o mundo digital

Uma nova forma de comunicação que vem conquistando cada vez mais espaço entre as mulheres é a Internet. Como "[...] meio de comunicação, de interação e de organização social[...]” (CASTELLS, 2003: 255), a Internet favorece a transformação da sociedade para uma sociedade em rede.

Segundo o artigo Flores Tecnológicas, de Rosa Alegria, "[...] quando falamos das novas funções de comunicação na Internet, falamos dos padrões femininos de se comunicar. Comunicar-se para as mulheres é essencialmente criar relacionamentos."

A questão da globalização e esses novos meios de comunicação deixam as diferenças sociais mais evidentes devido, principalmente, à enorme quantidade de informação disponível e alto custo para acesso.

"O processo de globalização que agora vivemos, no entanto, é ao mesmo tempo um movimento de potencialização da diferença e de exposição constante de cada cultura às outras, de minha identidade àquela do outro. [...] Misturar o plano coletivo das culturas com aquele dos individuos, que se movem em planos claramente diversos, permite sem dúvida constatar que aquilo que acontece em um produz efeitos no outro: o reconhecimento das diferenças culturais tradicionais - étnicas e raciais - tanto quanto o das modernas de gênero ou dos homossexuais - passa sem dúvida pelo plano dos direitos e das leis, po- 
MULHER E TECNOLOGIA: A ASSIMILAÇÃO E UTILIZAÇÃO DO MUNDO DIGITAL POR EXECUTIVAS

DE COMUNICAÇÃO • ANA MARIA FRANCHON

rém eles só se realizam no reconhecimento cotidiano dos direitos e no respeito dos indivíduos que encarnam essas culturas". (MARTÍN-BARBERO, 2003: 60 e 61).

Em 1996, a pesquisa Cadê/Ibope constatou que $17 \%$ das pessoas que acessavam a Internet no Brasil eram mulheres. Em meados de 1997, realizou-se uma nova pesquisa em que se avaliou que esse número aumentou para $25 \%$. A pesquisa apontou também que é o sexo feminino o que mais se interessa pelo comércio eletrônico também no Brasil. No entanto, muitas mulheres ainda se dizem assustadas com os códigos dessa linguagem, que tem muitas características masculinas, como a sua linearidade e racionalidade tecnológica.

Além disso, a concepção e o design das novas tecnologias ainda estão pautados nas diferenças - entre ricos e pobres (que podem ou não pagar para ter acesso à tecnologia), entre quem fala e não fala inglês, entre homens e mulheres. Nessa última questão, é preciso repensar a realidade tecnológica e a realidade da mulher. Ao invés da mulher trabalhar com a tecnologia, os produtos também deveriam ser "feminilizados" a fim de que eles trabalhem para as mulheres.

\section{Estudo de caso}

Para a análise da relação da mulher pós-moderna com a tecnologia no seu universo de trabalho, foi estabelecido o estudo do caso da área de comunicação de um grupo do setor financeiro. Foram realizadas 10 entrevistas com os executivos da área de comunicação do Grupo. O departamento é constituído em sua maioria por mulheres (cerca de $71 \%$ dos funcionários do departamento são do sexo feminino).

Pode-se dizer que a área de comunicação é formada, em sua maioria, por mulheres jovens ( $50 \%$ dos entrevistados têm menos de 30 anos de idade), com ensino superior completo $(70 \%)$ e especialização $(30 \%)$. A formação acadêmica entre os entrevistados variou bastante, sendo a maioria jornalistas (30\%) ou relações-públicas $(20 \%)$ ou, ainda, publicitários $(20 \%)$.

Todos os entrevistados disseram conhecer os programas do Pacote Office (Word, Excel e Power Point) e a grande maioria dos entrevistados disse possuir dois e-mails, um para uso profissional (endereço do Banco) e outro para uso pessoal. Todos possuem celular, sendo que alguns até afirmaram que o aparelho é uma necessidade do próprio trabalho. Porém, apenas dois entrevistados disseram ter página na Internet, blog ou cadastro no Orkut e a idade destes entrevistados está na faixa entre 21 e 30 anos. Se, por um lado, os mais jovens parecem estar mais familiarizados com as novidades da Internet, as duas entrevistadas que possuem laptop têm idade superior a 31 anos. Isto acontece, provavelmente, por exercerem cargos mais elevados e terem salários mais altos para poder ter acesso a um gadget mais caro. 
As opiniões foram bastante divididas com relação ao relacionamento dos entrevistados com a tecnologia: enquanto metade afirmou gostar de estar atualizado com as novidades, a outra metade disse só usar o que for indispensável para o trabalho. De qualquer forma, pode-se notar uma certa resistência em opiniões como a de uma das entrevistadas: "Não me interesso muito não e acho que não tenho muita familiaridade. Só uso tecnologia por necessidade. Não faço muita questão de conhecer as novidades". Um motivo alegado por duas entrevistadas para não estarem tão atualizadas como gostariam foi a falta de tempo, como afirma uma delas: "É uma relação boa, amigável, gosto de estar atualizada, mas tenho pouco tempo para isso. Falta tempo para aprender a utilizar. Depois que aprendo a usar, gosto das novidades”.

A maioria dos entrevistados concordou com a afirmação de que a tecnologia facilitou o trabalho $(70 \%)$, tornando-o mais rápido $(50 \%)$, dinâmico $(20 \%)$ e organizado (20\%). Porém, alguns problemas foram apontados, como no depoimento: "Facilitou, mas a gente acaba trabalhando de uma forma muito impessoal. Perde menos tempo, mas é impessoal e dificulta o trabalho em equipe". Ou, ainda, a questão da dependência com relação à tecnologia, em um mundo onde não é possível o trabalho sem computador: "E-mail e celular são ferramentas primordiais e essenciais para o meu trabalho. Por exemplo, um microcomputador offline impossibilita o trabalho".

Ao contrário do que se pensava, os entrevistados não acreditam que seu departamento utiliza mais tecnologia que os demais (70\%). Isto não significa que o departamento usa pouca tecnologia, mas é reflexo de uma empresa que necessita de muita tecnologia na prestação de serviços como um todo. Além disso, o uso de tecnologia em uma área de relacionamento é visto negativamente, já que acredita-se que ela cause uma certa impessoalidade: "Nosso departamento não é o que usa mais, mas, na maior parte do tempo, a gente usa a Internet e intranet. Na realidade, como é uma área de relacionamento, dependemos ainda do contato pessoal", alegou outra entrevistada.

$80 \%$ dos entrevistados acreditam que as ações de comunicação que utilizam tecnologia proporcionam um feedback mais favorável. Um dos depoimentos comprova esta afirmação: "nessa rotina que temos aqui, sim. Porque facilita a vida, é mais rápido, viável, economiza papel e é mais acessível". Por outro lado, alguns ainda afirmam sentir a necessidade de materiais impressos: "eu acho que os materiais impressos ainda têm forte apelo. Eles ainda não foram substituídos" ou ainda: "por exemplo, hoje eu recebi um comunicado via Internet que tive que imprimir. Às vezes não consigo ler algo na tela. Para me concentrar melhor, preciso ter o arquivo impresso”.

Quando se comparou a facilidade de homens e mulheres para lidar com a tecnologia, pouco mais da metade dos entrevistados (60\%) disse que parece que o homem tem mais facilidade. As razões que sustentam esta crença são: os homens exploram mais 
as potencialidades da tecnologia (60\%), têm mais interesse $(20 \%)$ ou por uma questão cultural (20\%). Para uma das entrevistadas, "os homens que eu conheço têm mais facilidade que eu. Eu acho que eles têm mais interesse pela máquina, pelo que ela pode oferecer".

Por outro lado, algumas entrevistadas afirmaram que, para elas, a mulher tem mais facilidade para assimilar a tecnologia que os homens: "as mulheres pegam mais fácil, são mais perspicazes. O homem fica focado num ponto só. As mulheres têm uma visão mais global das coisas".

A maioria dos entrevistados utiliza a Internet para o trabalho e para o lazer. Foi interessante verificar que, na área de comunicação, os sites de notícia são os mais visitados, seja para comparar informações, ou para pesquisa sobre as práticas da concorrência (benchmarking).

Todos os entrevistados acreditam que houve um distanciamento das mulheres em relação à vida moderna. $30 \%$ dos entrevistados concordaram que a tecnologia ajudou nesse afastamento e outros $30 \%$ afirmaram que esse afastamento ocorreu devido à entrada da mulher no mercado de trabalho. Um depoimento interessante foi: "eu moro sozinha e não sei cozinhar. O mundo moderno influenciou este distanciamento. A mulher usa o tempo para outras coisas, como ficar na Internet. São vários fatores que influenciaram o distanciamento, como a saída da mulher para o mercado de trabalho".

Outros depoimentos que podem ser destacados são: "houve um distanciamento, sim. Apesar de as mulheres trabalharem muito, ainda existe a preocupação com os filhos e a casa. A tecnologia ajudou a mulher a compatibilizar a vida em casa com o trabalho. Ela proporcionou mais tempo para cuidar da casa”. Já outra entrevistada ressaltou a falta de tempo que ainda persiste: "Muito pouco [distanciamento]. Na medida em que não se tem horário para nada, a tecnologia acabou reduzindo o tempo das pessoas para outras atividades que não o trabalho".

Para os entrevistados que discordaram da afirmação de que foi a tecnologia que possibilitou a inserção das mulheres no mercado de trabalho, outros motivos tiveram maior influência. Um dos entrevistados, por exemplo, afirmou: "acho que não foi devido à tecnologia e sim por outros motivos, como a própria mudança de postura da mulher e predisposição do mercado".

A questão da falta de tempo retornou à entrevista quando foi perguntado se os entrevistados concordam com a afirmação de que a tecnologia disponibilizou mais tempo para a mulher cuidar de si mesma. $60 \%$ dos entrevistados disse concordar com a afirmação, inclusive, justificando: "como as informações vêm mais rápidas, sobra mais tempo para se cuidar". Por outro lado, outra entrevistada acha que as mulheres con- 
tinuam sem tempo e ainda completa que discorda parcialmente da afirmação: "porque [com a tecnologia] te encontram em qualquer lugar”.

A entrada da mulher no mercado de trabalho parece ter incentivado sua procura por cursos de capacitação também na área de tecnologia. Todos os entrevistados acreditam que a mulher está mais interessada em aprender sobre tecnologia, sendo que metade deles acredita que isso aconteceu devido ao aumento da concorrência no mercado de trabalho. Como finaliza outra entrevistada, "a mulher procurou cursos porque está no mercado e disputa pau-a-pau com a ala masculina e com outras mulheres também".

\section{Considerações finais}

Comparando-se o levantamento teórico com a pesquisa de campo realizada, pode-se constatar a legitimidade de várias das informações apresentadas. Tornaram-se visíveis as alterações sofridas pelo modelo de gestão organizacional, que ainda não conseguiu adaptar-se completamente às rápidas transformações econômicas, tecnológicas e, por que não acrescentar, a problemática social das mulheres na nova realidade.

A entrada da mulher no mercado de trabalho do homem já é fato irrefutável. Porém, a sociedade parece ainda não ter conseguido se organizar de forma a atender a nova demanda social, oferecendo melhores condições de trabalho, salários mais justos e, em especial, acreditando no potencial feminino de liderança, especialmente na área da comunicação.

A transformação do papel da mulher na sociedade ficou bastante visível durante o desenvolvimento da pesquisa de campo. Agora, além das suas atividades relacionadas à casa e à família, a mulher procura cada vez mais seu próprio espaço em um mercado de trabalho extremamente competitivo.

A mulher quer conquistar seu lugar na sociedade pós-moderna através de seu esforço próprio e sente a necessidade crescente de capacitação profissional e atualização para poder competir de igual para igual, seja com os homens ou com as próprias mulheres que já estão no mercado. E, para estar atualizada, a mulher de hoje, em especial a executiva de comunicação, abordada na pesquisa do estudo de caso, parece conhecer a importância do domínio das mais modernas ferramentas tecnológicas.

O estreitamento da relação entre mulheres, Comunicação e tecnologia pode ser apontado como uma forte tendência. Se, anteriormente, o papel desempenhado pela mulher era de coadjuvante, agora, a necessidade da sua entrada no mercado de trabalho aponta novos caminhos. Instrumentos evidentes de poder, como a informação (dis- 
MULHER E TECNOLOGIA: A ASSIMILAÇÃO E UTILIZAÇÃO DO MUNDO DIGITAL POR EXECUTIVAS

DE COMUNICAÇÃO • ANA MARIA FRANCHON

seminada por meio da comunicação) e a tecnologia, antes privilégios exclusivos de uso masculino, tornam-se cada vez mais acessíveis às mulheres.

$\mathrm{Na}$ área de comunicação, as profissionais estão cada vez mais empregando tecnologia para proporcionar agilidade, dinamismo e rapidez ao seu trabalho. Porém, não se esquecem de que uma comunicação efetiva também depende de bons relacionamentos, e relacionamentos também dependem do contato pessoal com o público para quem se quer transmitir uma mensagem.

Portanto, as executivas de Comunicação parecem bastantes cientes de que não deve haver deslumbramento no emprego da tecnologia em seu campo de trabalho. Para elas, apesar do reconhecimento da importância do aprendizado da utilização das novas tecnologias, a área de comunicação continua tendo como essência o relacionamento interpessoal, que demonstra maior efetividade e durabilidade da recepção das informações transmitidas.

\section{Bibliografia}

ALEGRIA, Rosa. Flores Tecnológicas. Disponível em http://www.perspektiva.com.br/futuro/flores_tecnologicas.htm . Acesso em 20 de abril de 2004.

ARAÚJO, Betania Maciel de; SANCHES, Conceição A.; LOPES, Tânia. Mulher e Tecnologia. In: III Encontro Lusófono de Ciências da Comunicação. Universidade do Minho. Braga, Portugal, 27 a 30 de outubro de 1999 CT: Tecnologia, Media e Sociedade. Disponível em http://www.sabbatini.com/bemaciel/textos/lusocom99.htm. Acesso em 21 de abril de 2004.

BOURDIEU, Pierre. A dominação masculina. Rio de Janeiro: Bertrand Brasil, 1999.

CASTELLS, Manuel. Internet e sociedade em rede. In: MORAES, Dênis de (org.). Por uma outra Comunicação. Rio de Janeiro: Record, 2003.

DE MASI, Domenico. O ócio criativo. Rio de Janeiro: Sextante, 2000.

DIAS, lara de Jesus. Mulheres jornalistas. Dissertação de Mestrado. São Paulo: ECA-Universidade de São Paulo, 2001.

FREITAS, Sidinéia Gomes de. A Comunicação Social como instrumento de poder. As coordenadorias de Comunicação Social da "Nova República". Tese de doutorado. São Paulo: ECA-Universidade de São Paulo, 1987.

GRUNIG, James E. A função das Relações Públicas na Administração e sua contribuição para a efetividade organizacional e societal. In: Revista Comunicação e Sociedade. São Bernardo do Campo: Póscom-Umesp, ano 24, n. 39, $1^{\circ}$ semestre, 2003. 
MULHER E TECNOLOGIA: A ASSIMILAÇÃO E UTILIZAÇÃO DO MUNDO DIGITAL POR EXECUTIVAS DE COMUNICAÇÄO - ANA MARIA FRANCHON

HARVEY, David. Condição pós-moderna. São Paulo: Loyola, 1993.

KUNSCH, Margarida Maria Krohling. Planejamento de Relações Públicas na Comunicação Integrada. São Paulo: Summus, 2003.

LEMOS, André; PALACIOS, Marcos. As janelas do ciberespaço. Porto Alegre: Sulina, 2001.

MARTÍN-BARBERO, Jesús. Globalização comunicacional e transformação cultural. In: MORAES, Dênis (org.). Por uma outra Comunicação. Rio de Janeiro: Record, 2003.

NEGROPONTE, Nicholas. A vida digital. São Paulo: Companhia das Letras, 1995.

PESSONI, Arquimedes. As mulheres dão o tom no VI Celacom. In: Revista Comunicação e Sociedade. São Bernardo do Campo: Póscom-Umesp, ano 24, n. 39, 1ºmestre, 2003.

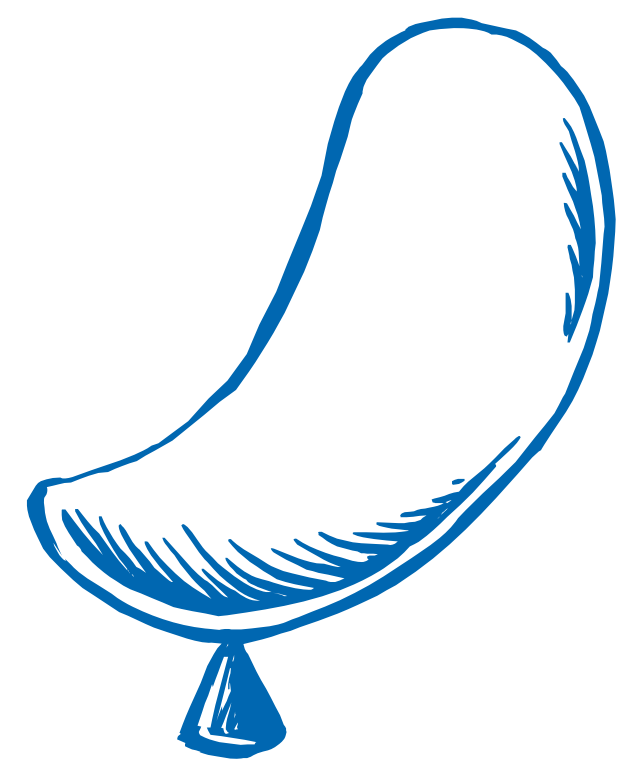

ANO $2 \cdot$ NÚMERO $3 \cdot 2^{\circ}$ SEMESTRE DE $2005 \cdot$ organicom • 129 